\title{
Carfilzomib boosted combination therapy for relapsed multiple myeloma
}

This article was published in the following Dove Press journal:

OncoTargets and Therapy

15 February 2017

Number of times this article has been viewed

\author{
Raphael E Steiner \\ Elisabet E Manasanch \\ Department of Lymphoma and \\ Myeloma, The University of Texas MD \\ Anderson Cancer Center, Houston, \\ TX, USA
}

\begin{abstract}
Carfilzomib is a proteasome inhibitor that binds selectively and irreversibly to the $20 \mathrm{~S}$ proteasome, the proteolytic core particle within the $26 \mathrm{~S}$ proteasome, resulting in the accumulation of proteasome substrates and ultimately growth arrest and apoptosis of tumor cells. The development and ultimate approval of this medication by regulatory agencies has been an important step toward improving clinical outcomes in multiple myeloma. Although initially approved as a single agent for the treatment of multiply relapsed and/or refractory myeloma, in the USA, it is now widely used in the early relapse setting in combination with lenalidomide and dexamethasone. Carfilzomib has also been studied in combination with second-generation immunomodulatory drugs, histone deacetylase inhibitors, alkylating agents and other novel medications. In this review article, we will discuss the efficacy, safety, tolerability and quality of life of carfilzomib-based combination therapies, as well as novel agents, for relapsed multiple myeloma.
\end{abstract}

Keywords: multiple myeloma, relapsed and refractory myeloma, carfilzomib, novel drugs, salvage chemotherapy

\section{Introduction}

Multiple myeloma (MM) accounts for approximately $1 \%$ of all cancers and slightly $>10 \%$ of hematologic malignancies in the USA. ${ }^{1}$ Over the years, notable progress has been made in autologous stem cell transplantation (ASCT) along with the introduction of several breakthrough drugs, including newer generation immunomodulators (IMiDs) and proteasome inhibitors (PIs), which led to a significant increase in the response rate of those affected as well as survival rate. In fact, 5-year survival rates have almost doubled, increasing from $27 \%$ to $47 \%$ between 1989 and 2010, respectively. ${ }^{2,3}$

Despite the fact that recent treatment options for MM have led to improved response rates and increased survival, the vast majority of patients with MM ultimately relapse. Although second and later remissions can be achieved with additional treatment, tumors typically recur more aggressively after each relapse, leading to decreased duration of response and ultimately culminating in the development of treatment-refractory disease, which is associated with shortened survival times. ${ }^{4}$ As a consequence, combination therapy regimens are frequently used to treat patients with relapsed MM, with those that use the complementary activity of a PI and an IMiD particularly encouraging. ${ }^{5}$

There is now a plethora of treatments available for relapsed and refractory MM. In this review article, our aim is to discuss the therapeutic efficacy, safety and quality of life of carfilzomib regimens in combination with IMiDs (lenalidomide or pomalidomide) and other agents in the context of the vast array of novel therapies available for the treatment of relapsed and/or refractory MM (RRMM). We will also briefly discuss emerging new therapies for relapsed myeloma.
Correspondence: Elisabet E Manasanch Department of Lymphoma and Myeloma, The University of Texas MD Anderson Cancer Center, I5I5 Holcombe Blvd, Unit 429, Houston, TX, USA

Tel + I 7137455067

Fax + I 7I35635067

Email eemanasanch@mdanderson.org
OncoTargets and Therapy 2017:10 895-907

(c) (7) (\$) 2017 Steiner and Manasanch. This work is published and licensed by Dove Medical Press Limited. The full terms of this license are available at https://www.dovepress.com/terms.php (c) ${ }_{\mathrm{BY}} \mathrm{NC}$ and incorporate the Creative Commons Attribution - Non Commercial (unported, v3.0) License (http://(creativecommons.org/licenses/by-n/3.0.). By accessing the work you hereby accept the Terms. Non-commercial uses of the work are permitted without any further permission from Dove Medical Press Limited, provided the work is properly attributed. For permission for commercial use of this work, please see paragraphs 4.2 and 5 of our Terms (https://www.dovepress.com/terms.php). 


\section{Pharmacology, mode of action and biomarkers of carfilzomib}

The proteasome is a key structure for cell regulation at the interplay of cell division, angiogenesis, immune response, transcription factor activation and posttranslational modification of proteins. ${ }^{6}$ Carfilzomib is a tetrapeptide epoxyketone PI that binds selectively and irreversibly to the 20 S proteasome, the proteolytic core particle within the $26 \mathrm{~S}$ proteasome. Consequently, proteasome function after therapy can only be regained by de novo proteasome synthesis. Specifically, carfilzomib inhibits the chymotrypsin-like (CT-L) catalytic activity of the $\beta 5$ subunit over the caspase-like catalytic activity of the $\beta 1$ subunit or the trypsin-like catalytic activity of the $\beta 2$ subunit, resulting in the accumulation of proteasome substrates and ultimately growth arrest and apoptosis. ${ }^{5}$ Carfilzomib penetrates all tissues, but the brain extensively. It is largely metabolized extrahepatically and rapidly cleared from the circulation by biliary and renal excretion ( $\mathrm{t} 1 / 2=15-30$ minutes); $<1 \%$ is excreted intact. ${ }^{7}$

A novel constitutive/immunoproteasome subunit enzymelinked immunosorbent assay was used in a study to quantify proteasome subunit occupancy in samples from five Phase I/ II and II trials before and after treatment with carfilzomib. ${ }^{8}$ Following the first carfilzomib dose $\left(15-56 \mathrm{mg} / \mathrm{m}^{2}\right)$, a dosedependent inhibition of constitutive (c20S) and immuno (i20S) proteasome CT-L active sites was observed, where greater occupancy of multiple i20S subunits correlated with an increased likelihood of achieving a clinical response at higher doses of carfilzomib. ${ }^{8}$

Circulating proteasomes (cProteasomes) in blood have also been studied in myeloma as a potential biomarker. In a retrospective study, lower levels of cProteasomes after treatment were correlated with response to chemotherapy and improved survival. ${ }^{9}$ Unfortunately, these results were not replicated in a prospective study after initial treatment of myeloma patients with carfilzomib, lenalidomide and dexamethasone. ${ }^{10,11}$ This lack of association may be due to great efficacy of the combination treatment or the fact that cProteasomes activity is not reflective of the proteasome activity of malignant plasma cells, for example. Presently, there is no validated biomarker able to predict the clinical outcomes after treatment with carfilzomib. This is an aspect that needs to be further investigated in future studies.

\section{Efficacy of carfilzomib combination therapy}

Numerous trials have supported the clinical efficacy of carfilzomib whether in monotherapy or in combination (Table 1).
Thus, carfilzomib has undergone several approvals by the Food and Drug Administration (FDA) in the USA. It first received accelerated approval in 2012 in combination with dexamethasone for the treatment of RRMM patients who had received at least two prior lines of therapy, including bortezomib and an immunomodulatory drug. ${ }^{12}$ In 2015 , carfilzomib approval indication was expanded to include the combination with lenalidomide and dexamethasone for the treatment of patients with relapsed MM who had received one to three prior lines of therapy. ${ }^{13}$ In 2016, carfilzomib's approval in combination with dexamethasone was expanded to include treatment of RRMM patients, who had received one or more lines of therapy. Approval by the European Medicines Agency was received in 2015 in combination with either lenalidomide and dexamethasone or dexamethasone alone for patients with MM who had received at least one prior therapy. ${ }^{14}$

Carfilzomib was initially evaluated in two Phase I studies, PX-171-001 ${ }^{15}$ and PX-171-002, ${ }^{16}$ investigating two different dosing schedules for patients with RRMM: five consecutive days of a 14-day cycle and two consecutive days every week for 3 weeks of a 28-day cycle. The first schedule demonstrated promising antitumor activity, but the second one was better tolerated and was chosen for further exploration in Phase II studies. ${ }^{15,16}$

In the pivotal Phase II study PX-171-003-A1 of patients with RRMM, single-agent carfilzomib was efficacious, with an acceptable safety and tolerability profile when administered intravenously for two consecutive days/week for 3 weeks of a 28-day cycle at a dose reduced first cycle of $20 \mathrm{mg} / \mathrm{m}^{2}$ to abrogate potential tumor lysis syndrome and early infusion reaction and the dose escalated to $27 \mathrm{mg} / \mathrm{m}^{2}$ thereafter, with an overall response rate (ORR) of $23.7 \% .^{17,18}$ Other carfilzomib dosing schedules have been investigated with increasing activity. For example, a Phase I study of a 30-minute infusion of carfilzomib (on days 1, 2, 8, 9, 15, 16 every 28 days) with low-dose dexamethasone (40 mg weekly) in RRMM showed that the maximum tolerated dose (MTD) was $56 \mathrm{mg} / \mathrm{m}^{2}$. The ORR for this study for the $56 \mathrm{mg} / \mathrm{m}^{2}$ cohort was $55 \% .{ }^{19}$ Also, the CHAMPION-1 study evaluated carfilzomib on a once-weekly dosing schedule with the extension of the infusion time from 2-10 to 30 minutes to allow tolerance of higher doses of carfilzomib. In the Phase 1 portion of the study, the MTD of carfilzomib with dexamethasone was determined to be $70 \mathrm{mg} / \mathrm{m}^{2}$ once a week with an ORR of $77 \% .^{20}$

Based on the above encouraging results, the combination of carfilzomib, lenalidomide and dexamethasone for 
Table I Efficacy of carfilzomib combination therapy

\begin{tabular}{|c|c|c|c|c|}
\hline Author & $\begin{array}{l}\text { Phase } \\
\text { Primary end point } \\
\text { Regimen }\end{array}$ & $\begin{array}{l}\text { Patient population } \\
\text { with RRMM }\end{array}$ & Toxicities & Results \\
\hline $\begin{array}{l}\text { Stewart } \\
\text { et } \mathrm{a}^{23}\end{array}$ & $\begin{array}{l}\text { III Randomized } \\
\text { PFS } \\
\text { KRd vs Rd }\end{array}$ & $\begin{array}{l}396 \mathrm{KRd} \text { patients vs } \\
396 \mathrm{Rd} \text { patients }\end{array}$ & $\begin{array}{l}\text { AE grade } 3 \text { or higher in } \\
83.7 \% \mathrm{KRd} \text { and } 80.7 \% \mathrm{Rd}\end{array}$ & $\begin{array}{l}\text { ORR } 87.1 \% \text { KRd vs } 66.7 \% \text { Rd } \\
\text { Median PFS } 26.3 \text { months KRd vs } 17.6 \text { months Rd } \\
\text { 24-month OS } 73.3 \% \text { KRd vs } 65 \% \text { Rd }\end{array}$ \\
\hline $\begin{array}{l}\text { Dimopoulos } \\
\text { et } \mathrm{al}^{25}\end{array}$ & $\begin{array}{l}\text { III Randomized } \\
\text { PFS } \\
\text { Kd vs Vd }\end{array}$ & $\begin{array}{l}464 \mathrm{Kd} \text { patients vs } \\
465 \mathrm{Vd} \text { patients }\end{array}$ & $\begin{array}{l}\text { Higher rate of grade } 3-4 \\
\text { anemia, hypertension, } \\
\text { thrombocytopenia in } \mathrm{Kd}\end{array}$ & $\begin{array}{l}\text { ORR } 77 \% \text { Kd vs } 63 \% \text { Vd } \\
\text { Median PFS } 18.7 \text { months Kd vs } 9.4 \text { months Vd }\end{array}$ \\
\hline Wang et $\mathrm{al}^{22}$ & $\begin{array}{l}\text { II } \\
\text { ORR, PFS, DOR } \\
\text { KRd }\end{array}$ & $54 \mathrm{KRd}$ patients & $\begin{array}{l}\text { Lymphopenia, neutropenia, } \\
\text { thrombocytopenia and } \\
\text { anemia }\end{array}$ & $\begin{array}{l}\text { ORR } 76.9 \% \text { KRd } \\
\text { Median DOR } 22.1 \text { months KRd } \\
\text { Median PFS I5.4 months KRd }\end{array}$ \\
\hline Fiala et $\mathrm{a}^{35}$ & $\begin{array}{l}\text { II } \\
\text { Efficacy, ORR } \\
\text { KLd }\end{array}$ & $23 \mathrm{KLd}$ patients & $\begin{array}{l}\text { Infections, hypertension, } \\
\text { MI, thrombocytopenia, } \\
\text { anemia }\end{array}$ & $\begin{array}{l}\text { ORR } 83 \% \text { KLd } \\
\text { Median EFS } 7.4 \text { months }\end{array}$ \\
\hline $\begin{array}{l}\text { Berdeja } \\
\text { et }\left.a\right|^{32}\end{array}$ & $\begin{array}{l}\text { I/II } \\
\text { MTD, ORR } \\
\text { FKd }\end{array}$ & 33 FKd patients & $\begin{array}{l}\text { Dyspnea, neuropathy, } \\
\text { cardiac toxicities }\end{array}$ & $\begin{array}{l}\text { ORR } 82 \% \text { FKd } \\
\text { Median PFS } 9.7 \text { months } \\
\text { Median OS } 24.7 \text { months }\end{array}$ \\
\hline $\begin{array}{l}\text { Martin } \\
\text { et } \mathrm{al}^{72}\end{array}$ & $\begin{array}{l}\text { lb } \\
\text { MTD } \\
\text { IK }\end{array}$ & I I IK patients & $\begin{array}{l}\text { Anemia, neutropenia, } \\
\text { pneumonia }\end{array}$ & ORR $80 \%$ IK \\
\hline $\begin{array}{l}\text { Vesole } \\
\text { et al }{ }^{30}\end{array}$ & $\begin{array}{l}\text { MTD, safety } \\
\text { QUAD }\end{array}$ & I7 QUAD patients & $\begin{array}{l}\text { Neutropenia, anemia, } \\
\text { thrombocytopenia }\end{array}$ & $\begin{array}{l}\text { MTD not reached } \\
\text { No DLT observed } \\
\text { ORR } 53 \% \text { QUAD } \\
\text { Median PFS } 12 \text { months QUAD }\end{array}$ \\
\hline $\begin{array}{l}\text { Jakubowiak } \\
\text { et al }{ }^{37,38}\end{array}$ & $\begin{array}{l}\text { MTD, safety, efficacy } \\
\text { SKd }\end{array}$ & I8 SKd patients & $\begin{array}{l}\text { Thrombocytopenia, } \\
\text { neutropenia, anemia, } \\
\text { gastrointestinal disorders }\end{array}$ & $\begin{array}{l}\text { MTD not reached } \\
\text { I DLT of cardiac amyloidosis } \\
75 \% \geq \text { MR SKd }\end{array}$ \\
\hline Shah et $\mathrm{al}^{26}$ & $\begin{array}{l}\text { I } \\
\text { MTD, safety } \\
\text { KPd }\end{array}$ & $32 \mathrm{KPd}$ patients & Anemia, dypsnea & $\begin{array}{l}\text { ORR } 50 \% \text { KPd } \\
\text { Median PFS } 7.2 \text { months KPd }\end{array}$ \\
\hline
\end{tabular}

Abbreviations: AE, adverse event; DLT, dose-limiting toxicities; DOR, duration of response; EFS, event free survival; FKd, panobinostat carfilzomib dexamethasone; IK, isatuximab carfilzomib; $\mathrm{Kd}$, carfilzomib dexamethasone; KLd, carfilzomib pegylated liposomal doxorubicin dexamethasone; KPd, carfilzomib pomalidomide dexamethasone; KRd, carfilzomib lenalidomide dexamethasone; MI, myocardial infarction; MR, minimal response; MTD, maximum tolerated dose; ORR, overall response rate; OS, overall survival; PFS, progression-free survival; QUAD, carfilzomib lenalidomide vorinostat dexamethasone; Rd, lenalidomide dexamethasone; RRMM, relapsed and/or refractory multiple myeloma; SKd, selinexor carfilzomib dexamethasone; Vd, bortezomib dexamethasone.

RRMM was investigated in early phase studies. The study PX-171-006 evaluated the safety, dosage and efficacy of this combination and established an MTD of carfilzomib $20 \mathrm{mg} / \mathrm{m}^{2}$ on days 1 and 2 of cycle one, $27 \mathrm{mg} / \mathrm{m}^{2}$ on days $8,9,15$ and 16 of cycle one and $27 \mathrm{mg} / \mathrm{m}^{2}$ on days $1,2,8$, 9,15 and 16 starting with cycle two, lenalidomide $25 \mathrm{mg}$ on days 1-21 and dexamethasone $40 \mathrm{mg}$ weekly every 28 days, with an ORR of $62.5 \%$ in relapsed myeloma patients after one to three prior regimens. An expansion cohort at the MTD showed the ORR was $77 \%$, including an ORR of $69 \%$ in bortezomib-refractory patients. ${ }^{21,22}$

The efficacy of the combination of carfilzomib, lenalidomide and dexamethasone (KRd) set the stage for the Phase III study ASPIRE, which compared KRd to lenalidomide and dexamethasone ( $\mathrm{Rd})$ in patients with relapsed MM who had received one to three prior treatments. ${ }^{23}$ Among the 396 patients treated in the KRd arm, the ORR reached $87 \%$ compared to $67 \%$ in the $\mathrm{Rd}$ group, with a median progression-free survival (PFS) of 26.3 and 17.6 months, respectively. The addition of carfilzomib to lenalidomide and dexamethasone led to significantly improved outcomes with a clinically relevant $31 \%$ decrease in the risk of disease progression or death and an increase of 8.7 months in the median PFS. At that time, no other regimens were associated with an equivalent duration of median PFS in the absence of transplantation. Also, a preplanned subgroup analysis of ASPIRE showed that KRd improved PFS in patients with high-risk cytogenetics (t[4;14], [14;16], del[17p]) by 9 months relative to $\mathrm{Rd} .{ }^{24}$ This study supported the evidence that combination therapy was highly effective in relapsed myeloma and possibly led to a new standard of care for the treatment of early relapse.

Given that carfilzomib was found to be efficacious in bortezomib-refractory patients, there was an interest in a head-to-head comparison of PI efficacy in a similar patient population. The ENDEAVOR study randomized 929 patients 
with RRMM to either carfilzomib $56 \mathrm{mg} / \mathrm{m}^{2}$ with dexamethasone or bortezomib $1.3 \mathrm{mg} / \mathrm{m}^{2}$ with dexamethasone with the primary endpoint being PFS. ${ }^{25}$ The proportion of patients achieving an objective response was $77 \%$ in the carfilzomib group, compared with $63 \%$ in the bortezomib group. The median PFS was 18.7 months in the carfilzomib group vs 9.4 months in the bortezomib group. Serious adverse events (AEs) were reported in $48 \%$ of 463 patients in the carfilzomib group and in $36 \%$ of 456 patients in the bortezomib group and included by order of frequency: anemia, hypertension, thrombocytopenia and infections. A higher proportion of patients had peripheral neuropathy in the bortezomib group (51\% all grades vs 19\%), but nephro-cardiac events were more common in the carfilzomib group (acute kidney failure $7 \%$ vs $4 \%$, cardiac failure $7 \%$ vs $2 \%$ ). This study led to expanded approval of carfilzomib in patients who had received one to three lines of therapy as discussed above.

Also, carfilzomib has been studied in combination with other IMiDs. A Phase I study of the combination of carfilzomib, pomalidomide and dexamethasone (KPd) included 32 patients with relapsed MM refractory to the most recent line of therapy and refractory to a regimen containing full dose lenalidomide. ${ }^{26}$ The participants received a median of seven cycles (range, 1-24) of KPd and the ORR was 50\% in this heavily pretreated patient population. After a median follow-up of 26.3 months (range, 1-37), the median PFS was 7.2 months. The median overall survival (OS) was 20.6 months with the 12-month OS rate being 67\%. Interestingly, among the five patients with high-risk deletion of the short arm of chromosome 17, the 12-month PFS rate was $60 \%$ and the 12-month OS rate was $80 \%$, which were better than the rates observed for the entire cohort $(29 \%$ and $67 \%$, respectively). This keeps in line with the possible efficacy of pomalidomide for high-risk MM carrying deletion $17 \mathrm{p} .{ }^{27}$

The combination of carfilzomib with an IMiD is part of the standard of care of treatment for early relapse in MM with unprecedented efficacy shown in large randomized studies as described above. Also, carfilzomib has been combined with numerous other agents. In the next few paragraphs, we will discuss selected novel combinations using carfilzomib that have shown encouraging preliminary efficacy and may move forward to regulatory approval.

Improved clinical outcomes have been achieved with the combination of histone deacetylase inhibitors (HDACis) and PI. ${ }^{28,29}$ Given this, quadruple therapy has also been studied in early phase studies with the combination of carfilzomib, lenalidomide, vorinostat (HDACi) and dexamethasone (QUAD) among 17 patients with RRMM having received at least one prior line of therapy. ${ }^{30}$ The treatment was well tolerated with a manageable safety profile. The ORR was $53 \%$ across all cycles of treatment. The median time to response for patients achieving a partial response (PR) or better was 2 months, and the median duration of response for patients achieving a PR or better was 15 months. The median PFS was 12 months, and the median OS was not reached. Panobinostat is a pan-deacetylase inhibitor that was FDA approved for the treatment of patients with MM who have received at least two prior regimens, including bortezomib and an immunomodulatory agent. ${ }^{31}$ This molecule was studied in a Phase $1 / 2$ trial in combination with carfilzomib and dexamethasone with 33 patients with RRMM after at least one line of treatment. Notable AEs were dyspnea (36\%), neuropathy (18\%) and two grade $3 / 4$ cardiac toxicities. The ORR was $82 \%$, the median PFS was 9.69 months, and the median OS was 24.7 months. Of note, a carfilzomib dose of $56 \mathrm{mg} / \mathrm{m}^{2}$ with panobinostat at $20 \mathrm{mg}$ was given in this schedule and it did not appear to result in increased cardiopulmonary toxicity, but dyspnea rates were higher in this cohort than previously reported. ${ }^{32}$

Alkylating agents are being studied in combination with carfilzomib for patients with relapsed and/or refractory myeloma. The study ISRCTN17354232 will assess the efficacy of the combination of carfilzomib vs bortezomib with cyclophosphamide and dexamethasone in the UK. The study will also assess the need for carfilzomib maintenance after initial treatment in patients at first relapse or refractory to no more than one line of treatment. The primary objective of the study is to report noninferiority activity through response rate after 24 weeks of treatment. ${ }^{33}$ Another study, NCT02056756, is evaluating the MTD of the combination of carfilzomib with bendamustine and dexamethasone for RRMM after at least one prior line of therapy. ${ }^{34}$ Results of this study are awaited within the next year.

Pegylated liposomal doxorubicin (anthracyclines) has been combined with carfilzomib and dexamethasone in a Phase 2 trial with 23 patients with RRMM after at least a line of therapy. The ORR was $83 \%$, with $48 \%$ achieving a complete or very good partial response (VGPR). The median number of cycles was 11 ; the median estimated event-free survival was 7.4 months at a median follow-up of 10.6 months. Grade 3/4 nonhematologic toxicity was uncommon, but included infections (11 patients), hypertension (four patients) and myocardial infarction (one patient). Grade 3/4 hematologic toxicity included thrombocytopenia (11 patients), anemia (eight patients) and neutropenia (seven patients). ${ }^{35}$ 
In addition, selinexor, an orally available novel member of the selective inhibitors of nuclear export ${ }^{36}$ class of compounds has shown promising responses in combination with carfilzomib and dexamethasone (SKd). In a Phase 1 study with 18 patients with RRMM, of which 16 responseevaluable patients were refractory to carfilzomib and of which 11 were refractory to carfilzomib combinations as their last line of therapy, $75 \%$ showed at least a minimal response. The combination of SKd demonstrates encouraging activity and safety in heavily pretreated, mostly carfilzomibrefractory myeloma. ${ }^{37,38}$

Isatuximab, an anti-CD38 monoclonal antibody that is not yet approved for the treatment of myeloma, has been combined with carfilzomib in a Phase $1 \mathrm{~b}$ trial with 11 patients with RRMM having received a median of 4.5 prior lines of therapy, showing a promising ORR of $80 \%$. Hematologic toxicity was mild with $9 \%$ grade $3 / 4$ anemia, $9 \%$ grade $3 / 4$ neutropenia, and the most frequent serious $\mathrm{AE}$ was grade 3 pneumonia.

It is important to note than in addition to all the combination therapies mentioned above, for patients with relapsed and refractory myeloma, carfilzomib has been successfully studied in newly diagnosed MM (NDMM). Indeed, a Phase $1 / 2$ study with KRd as a frontline treatment for NDMM showed high response rates with $62 \%$ near-complete response (nCR) and $42 \%$ stringent complete response (sCR) after a median of 12 cycles. ${ }^{39}$ These findings were replicated in a second Phase II study using KRd in NDMM. ${ }^{11}$ These encouraging results in NDMM led to the National Comprehensive Cancer Network inclusion of $\mathrm{KRd}$ as a treatment option for NDMM. ${ }^{40}$ An ongoing Phase 3 study (NCT01863550, ENDURANCE) will test whether carfilzomib vs bortezomib combined with lenalidomide and dexamethasone leads to a meaningful increase in OS for NDMM patients, which may lead to a new standard of care for patients with NDMM.

Carfilzomib combination therapies are also effective in NDMM not eligible for ASCT. A Phase 2 study with carfilzomib, cyclophosphamide and dexamethasone (KCyd) in patients with NDMM $\geq 65$ years of age or who were ineligible for ASCT showed that after a median of nine KCyd induction cycles, $95 \%$ of patients achieved at least a partial response, $71 \%$ achieved at least a VGPR, 49\% achieved at least an $\mathrm{nCR}$ and $20 \%$ achieved $\mathrm{sCR} .{ }^{41}$ These are encouraging results especially for patients in those countries where IMiDs are not routinely used for treatment of newly diagnosed myeloma and where the use of carfilzomib with alkylating agents might be advantageous.

\section{Safety, tolerability and quality of life with carfilzomib combination therapy}

Carfilzomib is generally well tolerated by patients with RRMM. In this section, we will review the reported side effects that are specifically associated with carfilzomib treatment, as well as overall safety and tolerability data.

In the ASPIRE trial, $70 \%$ of the patients in the KRd group and $78 \%$ of the patients in the Rd group discontinued treatment, most commonly owing to disease progression (39.8\% and $50.1 \%$, respectively) or AEs. ${ }^{23}$ In the KRd group, AEs resulted in a reduction of the carfilzomib dose in $11 \%$ of patients and a reduction of the lenalidomide dose in $43 \%$ of patients. AEs of any grade that occurred more frequently in the KRd group than in the Rd group by at least 5\% points included hypokalemia, cough, upper respiratory tract infection, diarrhea, pyrexia, hypertension, thrombocytopenia, nasopharyngitis and muscle spasms. The rate of discontinuation due to these events was $<1 \%$ in both groups. There was no meaningful difference between groups in the incidence of peripheral neuropathy $(17.1 \%$ in the carfilzomib group and $17.0 \%$ in the control group), which was an important finding given the treatment limitations with the first-generation PI, bortezomib. AEs of grade 3 or higher were reported in $83.7 \%$ of patients in the KRd group and $80.7 \%$ of patients in the $\mathrm{Rd}$ group, and serious AEs were reported in 59.7\% and 53.7\% of patients, respectively. In each treatment group, $6.9 \%$ of patients died owing to AEs. AEs leading to more than two deaths in either group were myocardial infarction (three in the KRd group and one in the Rd group), cardiac failure (one and three, respectively) and sepsis (three and two, respectively). In the ASPIRE trial, patients in the KRd group reported superior health-related quality of life (according to the score on the Quality of Life Questionnaire-Core 30 Global Health Status and Quality of Life scale) than those in the Rd control group during the 18 cycles of treatment, ${ }^{23}$ without negatively affecting patient-reported symptoms. ${ }^{42}$

Carfilzomib is known to be toxic to cardiomyocytes probably due to the accumulation of unfolded, damaged and undegraded proteins and induced apoptosis. ${ }^{43}$ This may be a class effect of PIs, as bortezomib has also been associated with cardiac events, although at a much lower rate. ${ }^{17}$ Indeed, PI putatively mediates effects on the cardiovascular system as a result of changes in endothelial nitric oxide synthase activity and nitric oxide (NO) levels. ${ }^{44}$ Loss of NO bioavailability leads to impaired vasodilation and endothelial dysfunction, and misregulation of $\mathrm{NO}$ homeostasis is associated with hypertension, coronary artery disease, congestive heart 
failure, peripheral artery disease, diabetes and chronic renal failure. ${ }^{44}$ According to FDA prescribing information, death due to cardiac arrest has occurred within a day of carfilzomib administration and new-onset or worsening of pre-existing congestive heart failure with decreased left ventricular function or myocardial ischemia have occurred following the administration of carfilzomib. Cardiac failure events (eg, cardiac failure congestive, pulmonary edema, ejection fraction decreased) were reported in $7 \%$ of patients. ${ }^{45}$ Similarly, in the ASPIRE study, the cardiac events grade 3 or higher occurred more commonly in the carfilzomib group than in the control group: cardiac failure $3.8 \%$ vs $1.8 \%$, ischemic heart disease $3.3 \%$ vs $2.1 \%$ and hypertension $4.3 \%$ vs $1.8 \% .^{23}$ In a retrospective single-center study, 26 patients out of 130 treated with carfilzomib presented criteria for significant cardiac AEs. Among these 130 patients, 93 showed a median echocardiographic ejection fraction drop from 55\% to $33 \%$. However, most patients in this study with reported serious cardiovascular events also had a history of cardiac events and exposure to doxorubicin which may predispose to cardiac events. ${ }^{46}$ Nevertheless, the risk of these rare, but serious complications can be mitigated with basic management strategies, including increasing the infusion time, dose modification if indicated, proper fluid management and appropriate monitoring, allowing the majority of patients to benefit fully from this potentially life-prolonging treatment. ${ }^{47}$

According to FDA prescribing information, pulmonary arterial hypertension was reported in $2 \%$ of patients treated with carfilzomib and was grade 3 or greater in less than $1 \%$ of patients, and dyspnea was reported in $35 \%$ of patients with grade 3 dyspnea occurring in 5\%. ${ }^{45}$ However, in the recent Phase 3 FOCUS trial comparing carfilzomib vs corticosteroids with optional cyclophosphamide, dyspnea all grades and grade 3 or greater occurred in $15 \%$ and $1 \%$, respectively, in the carfilzomib group and in $9 \%$ and $0 \%$, respectively, in the control group and pulmonary hypertension was not reported at all. ${ }^{48}$ It is reasonable to think that the management of AEs of carfilzomib has improved between these two studies, leading to a reduction of reported dyspnea. Nevertheless, it is unclear from these reports whether anemia or cardiac dysfunction contributed to dyspnea that was not related to pulmonary hypertension.

\section{Combination of FDA-approved therapies for the treatment of relapsed/refractory myeloma that do not include carfilzomib}

Combination therapies that do not include carfilzomib have changed the MM treatment landscape and have recently been approved by the regulatory agencies due to demonstrated efficacy in clinical trials. These include the monoclonal antibodies, HDACi, IMiDs and oral versions of PI, which are summarized in Table 2 and discussed below.

Since 2015, the introduction of monoclonal antibodies in the treatment of MM has been perhaps the major step forward in the treatment of this disease. Daratumumab is a human monoclonal antibody that binds to CD38, a molecule expressed by myeloma cells, and induces complement-dependent and antibody-dependent cell-mediated cytotoxicity, antibody-dependent cell phagocytosis, as well as induction of apoptosis. ${ }^{49}$ Daratumumab was studied initially as monotherapy, leading to regulatory approval by the FDA in 2015. Recently, a Phase I/II trial with daratumumab, lenalidomide and dexamethasone (DRd) among patients with relapsed MM after two to four prior lines of therapy resulted in rapid, deep and durable responses with an ORR of $81 \%$ (25\% sCR, 9\% complete response [CR] and 28\% VGPR). The 18-month PFS and OS rates were $72 \%$ and $90 \%$, respectively, which were very encouraging. ${ }^{50}$ Daratumumab has also been studied in combination with bortezomib. A Phase 3 trial randomized 498 patients with RRMM to receive bortezomib and dexamethasone alone or in combination with daratumumab. ${ }^{51}$ The 12-month rate of PFS was $60.7 \%$ in the daratumumab group vs $26.9 \%$ in the control group. The rate of overall response was higher in the daratumumab group than in the control group ( $82.9 \%$ vs $63.2 \%, P<0.001$ ), as were the rates of VGPR or better $(59.2 \%$ vs $29.1 \%, P<0.001)$ and CR or better $(19.2 \%$ vs $9.0 \%, P=0.001)$. Based on these studies, daratumumab improves clinical outcomes when combined with other antimyeloma agents in the RRMM setting. Based on these results, there are several studies ongoing that evaluate the efficacy of daratumumab for the initial treatment of myeloma, including a Phase III study of bortezomib, lenalidomide, dexamethasone with or without daratumumab (NCT02874742) for NDMM.

Elotuzumab is a humanized immunoglobulin G1 immunostimulatory monoclonal antibody targeted against signaling lymphocytic activation molecule F7. Elotuzumab exerts a dual effect by directly activating natural killer cells and mediating antibody-dependent cell-mediated cytotoxicity through the CD16 pathway. ${ }^{52,53}$ The Phase 3 ELOQUENT trial compared elotuzumab plus lenalidomide and dexamethasone (ERd) with lenalidomide and dexamethasone (Rd). ${ }^{53}$ The ORR in the ERd group was $79 \%$ vs $66 \%$ in the Rd group, and the median PFS in the ERd group was 19.4 vs 14.9 months in the $\mathrm{Rd}$ group. ${ }^{53}$ Based on this study, elotuzumab was approved for treatment by the FDA in 2015 
Table 2 Efficacy of novel FDA-approved combination therapies for the treatment of RRMM that do not include carfilzomib

\begin{tabular}{|c|c|c|c|c|}
\hline Author & $\begin{array}{l}\text { Phase } \\
\text { Primary end point } \\
\text { Regimen }\end{array}$ & $\begin{array}{l}\text { Patient population with } \\
\text { RRMM }\end{array}$ & Toxicities & Results \\
\hline $\begin{array}{l}\text { San Miguel } \\
\text { et } \mathrm{al}^{27}\end{array}$ & $\begin{array}{l}\text { III Randomized } \\
\text { PFS } \\
\text { Pd vs HD dex }\end{array}$ & $\begin{array}{l}302 \text { Pd patients vs I53 HD dex } \\
\text { patients }\end{array}$ & $\begin{array}{l}\text { Increased rate of neutropenia and } \\
\text { pneumonia in } \mathrm{Pd}\end{array}$ & $\begin{array}{l}\text { ORR } 31 \% \text { Pd vs } 10 \% \text { HD dex } \\
\text { Median PFS } 4.0 \text { months Pd vs } \\
\text { I. } 9 \text { months HD dex }\end{array}$ \\
\hline $\begin{array}{l}\text { San-Miguel } \\
\text { et } \mathrm{al}^{29}\end{array}$ & $\begin{array}{l}\text { III Randomized } \\
\text { PFS } \\
\text { FVd vs placebo }+ \text { Vd }\end{array}$ & $\begin{array}{l}387 \text { FVd patients vs } 38 \mathrm{I} \\
\text { placebo + Vd patients }\end{array}$ & $\begin{array}{l}\text { Increased rate of SAE, } \\
\text { thrombocytopenia and diarrhea } \\
\text { in FVd }\end{array}$ & $\begin{array}{l}\text { ORR } 60.7 \% \mathrm{FVd} \text { vs } 54.6 \% \text { placebo }+ \\
\text { Vd, } P=0.09 \\
\text { CR or } \mathrm{nCR} F \mathrm{Fd} 27.6 \% \text { vs } 15.7 \% \\
\text { placebo }+\mathrm{Vd} \\
\text { Median PFS } 12.0 \text { months } \mathrm{FVd} \text { vs } \\
8.1 \text { months placebo }+\mathrm{Vd} \\
\text { Median OS } 33.6 \text { months FVd vs } \\
30.4 \text { months placebo }+\mathrm{Vd}\end{array}$ \\
\hline $\begin{array}{l}\text { Lonial } \\
\text { et } \mathrm{al}^{53}\end{array}$ & $\begin{array}{l}\text { III Randomized } \\
\text { PFS, ORR } \\
\text { ERd vs Rd }\end{array}$ & $\begin{array}{l}32 \text { I ERd patients vs } 325 \mathrm{Rd} \\
\text { patients }\end{array}$ & $\begin{array}{l}\text { Increased rate of grade } 3-4 \\
\text { lymphocytopenia in ERd, increased } \\
\text { rate of neutropenia grade } 3-4 \text { in Rd }\end{array}$ & $\begin{array}{l}\text { ORR } 79 \% \text { in ERd vs } 66 \% \text { in Rd } \\
\text { Median PFS I } 9.4 \text { months in ERd vs } \\
\quad 14.9 \text { months in Rd }\end{array}$ \\
\hline $\begin{array}{l}\text { Moreau } \\
\text { et a }\left.\right|^{55}\end{array}$ & $\begin{array}{l}\text { III Randomized } \\
\text { PFS } \\
\text { NRd vs placebo + Rd }\end{array}$ & $\begin{array}{l}360 \text { NRd patients vs } 362 \text { placebo }+ \\
\text { Rd patients }\end{array}$ & $\begin{array}{l}\text { Similar rate of SAE in the two groups } \\
\text { Higher rate of rash, neuropathy and } \\
\text { grade } 3-4 \text { thrombocytopenia in NRd }\end{array}$ & $\begin{array}{l}\text { ORR } 78 \% \text { in NRd vs } 72 \% \text { in } R d \\
\text { CR + VGPR } 48 \% \text { in NRd vs } 39 \% \text { in Rd } \\
\text { Median PFS } 20.6 \text { months in NRd vs } \\
\quad 14.7 \text { months in Rd }\end{array}$ \\
\hline $\begin{array}{l}\text { Lonial } \\
\text { et } \mathrm{al}^{49}\end{array}$ & $\begin{array}{l}\text { II Randomized } \\
\text { ORR } \\
\text { Dara } 8 \text { vs } 16 \mathrm{mg} / \mathrm{kg}\end{array}$ & $\begin{array}{l}\text { Part I: I } 8 \text { patients Dara } 8 \mathrm{mg} / \mathrm{kg} \\
\text { vs } 16 \text { patients Dara } 16 \mathrm{mg} / \mathrm{kg} \\
\text { Part 2: } 106 \text { patients Dara } 16 \mathrm{mg} / \mathrm{kg}\end{array}$ & Fatigue, anemia & $\begin{array}{l}\text { ORR Dara } 16 \mathrm{mg} / \mathrm{kg} 29.2 \% \\
\text { Median PFS Dara } 16 \mathrm{mg} / \mathrm{kg} 3.7 \text { months } \\
\text { Median OS Dara } 16 \mathrm{mg} / \mathrm{kg} 17.5 \text { months }\end{array}$ \\
\hline Baz et $\mathrm{al}^{54}$ & $\begin{array}{l}\text { II Randomized } \\
\text { ORR } \\
\text { PCd vs Pd }\end{array}$ & 33 patients PCd vs 35 Pd patients & $\begin{array}{l}\text { Higher rate of grade } 3-4 \text { anemia, } \\
\text { thrombocytopenia and neutropenia } \\
\text { in PCd }\end{array}$ & $\begin{array}{l}\text { ORR } 64.7 \% \text { in PCd vs } 38.9 \% \text { in Pd } \\
\text { Median PFS } 9.5 \text { months in PCd vs } \\
4.4 \text { months in Pd }\end{array}$ \\
\hline $\begin{array}{l}\text { Kumar } \\
\text { et al }{ }^{57}\end{array}$ & $\begin{array}{l}\text { II } \\
\text { ORR } \\
\text { NCd }\end{array}$ & 78 patients NCd & $\begin{array}{l}\text { Diarrhea, nausea, anemia, } \\
\text { neutropenia }\end{array}$ & $\begin{array}{l}\text { ORR } 49 \% \\
\text { I } 2 \text {-month PFS } 57.5 \%\end{array}$ \\
\hline $\begin{array}{l}\text { Krishnan } \\
\text { et } \text { al }^{56}\end{array}$ & $\begin{array}{l}\text { I/II } \\
\text { MTD, efficacy } \\
\text { NPd }\end{array}$ & 32 NPd patients & $\begin{array}{l}\text { Neutropenia, lymphocytopenia, } \\
\text { thrombocytopenia }\end{array}$ & $\begin{array}{l}\text { ORR } 45 \% \text { NPd } \\
\text { ORR } 58 \% \text { in high-risk cytogenetics }\end{array}$ \\
\hline $\begin{array}{l}\text { Pozzi } \\
\text { et } \mathrm{al}^{58}\end{array}$ & $\begin{array}{l}\text { I/II } \\
\text { MTD, response } \\
\text { BRd }\end{array}$ & $\begin{array}{l}\text { Phase I: I } 5 \text { patients BRd } \\
\text { Phase II: } 23 \text { patients BRd }\end{array}$ & $\begin{array}{l}\text { Neutropenia, anemia, } \\
\text { thrombocytopenia, rash }\end{array}$ & $\begin{array}{l}\text { ORR } 47 \% \text { in BRd } \\
\text { Median PFS } 10 \text { months in BRd } \\
2 \text {-year OS } 65 \% \text { in BRd }\end{array}$ \\
\hline $\begin{array}{l}\text { Plesner } \\
\text { et } \mathrm{al}^{73}\end{array}$ & $\begin{array}{l}\text { I/II } \\
\text { Safety, efficacy } \\
\text { DRd }\end{array}$ & $\begin{array}{l}\text { Part I: I } 3 \text { patients DRd } \\
\text { Part 2: } 32 \text { patients DRd }\end{array}$ & $\begin{array}{l}\text { Neutropenia, anemia, } \\
\text { thrombocytopenia }\end{array}$ & $\begin{array}{l}\text { ORR } 81 \% \text { in DRd } \\
18 \text {-month PFS } 72 \% \text { in DRd } \\
\text { I8-month OS } 90 \% \text { in DRd }\end{array}$ \\
\hline
\end{tabular}

Abbreviations: BRd, bendamustine lenalidomide dexamethasone; CR, complete remission; Dara, daratumumab; dex, dexamethasone; DRd, daratumumab lenalidomide dexamethasone; ERd, elotuzumab lenalidomide dexamethasone; FDA, Food and Drug Administration; FVd, panobinostat bortezomib dexamethasone; HD, high dose; Id, ixazomib dexamethasone; MTD, maximum tolerated dose; NCd, ixazomib cyclophosphamide dexamethasone; nCR, near-complete remission; NPd, ixazomib, pomalidomide dexamethasone; NRd, ixazomib lenalidomide dexamethasone; ORR, overall response rate; OS, overall survival; PCd, pomalidomide cyclophosphamide dexamethasone; Pd, pomalidomide low-dose dexamethasone; PFS, progression-free survival; Rd, lenalidomide dexamethasone; RRMM, relapsed and/or refractory multiple myeloma; SAE, serious adverse events; Vd, bortezomib dexamethasone; VGPR, very good partial response.

and is now routinely used in clinical practice. Elotuzumab is being studied as part of initial treatment in Phase III studies for high-risk and standard risk NDMM (NCT02495922, NCT01668719).

Given their overall good tolerability and significant efficacy, monoclonal antibodies can be combined with numerous regimens to boost therapy for myeloma. Studies including monoclonal antibodies in combination with standard therapies for NDMM are ongoing, eagerly awaited and likely to reshape how we treat myeloma in the coming years. Panobinostat is a pan-deacetylase inhibitor that was FDA approved for the treatment of patients with MM who have received at least two prior regimens, including bortezomib and an immunomodulatory agent. ${ }^{37}$ This molecule was studied in the Phase 3 trial PANORAMA1 that randomized 768 patients to either panobinostat, bortezomib and dexamethasone (FVd) or placebo, bortezomib and dexamethasone (Vd). The median PFS and OS were longer in the FVd group than in the Vd-placebo group, 12.0 vs 8.1 months and $33.6 \mathrm{vs}$ 30.4 months, respectively. The proportion of patients with a $\mathrm{CR}$ or an $\mathrm{nCR}$ was also significantly higher in the $\mathrm{FVd}$ group than in the Vd-placebo group (27.6\% vs $15.7 \%){ }^{29}$ 
Pomalidomide has been studied in different combinations, including with carfilzomib as mentioned above and cyclophosphamide. A Phase II trial with 68 RRMM patients, who had received at least two prior lines of therapy including prior use of lenalidomide and lenalidomide-refractory patients, were randomized to receive pomalidomide, cyclophosphamide and dexamethasone (PCyd) or pomalidomide/ dexamethasone (Pd). The ORR was $64.7 \%$ vs $38.9 \%$ and the median PFS was 9.5 vs 4.4 months in the PCyd vs Pd arms, respectively, making this regimen another possible choice for patients with RRMM. ${ }^{54}$

Ixazomib is an oral PI studied in the Phase 3 trial TOURMALINE-MM1 with 722 patients who had relapsed, refractory, or relapsed and refractory MM receiving ixazomib plus lenalidomide-dexamethasone (NRd) or placebo plus lenalidomide-dexamethasone (placebo-Rd). ${ }^{55}$ The overall rates of response were $78 \%$ in the NRd group and $72 \%$ in the placebo-Rd group, and the PFS was significantly longer in the NRd group (20.6 months) than in the placebo-Rd group (14.7 months). Due to its demonstrated efficacy vs lenalidomide alone and convenience of an all-oral regimen, ixazomib is routinely used in the clinic for treatment of RRMM in the USA.

A Phase 1/2 trial with ixazomib, pomalidomide and dexamethasone with 32 patients with RRMM has also been reported. This showed an ORR of $45 \%$ and an ORR of $58 \%$ in patients with high-risk cytogenetics (1q, 17p, t[4;14]), adding evidence to the efficacy of pomalidomide's use in high-risk myeloma. ${ }^{56}$ Another trial with ixazomib, cyclophosphamide and dexamethasone including 78 patients showed a similar efficacy with an ORR of 49\%. However, a subgroup analysis showed a higher ORR (68\% vs 35\%), a higher CR+VGPR rate (23\% vs $12 \%$ ) and a significant PFS improvement in patients aged $>65$ years vs patients aged $\leq 65$ years $(12$-month PFS rate estimate $67.2 \%$ vs $50.7 \%) .{ }^{57}$

The alkylator agent bendamustine is also efficacious and is currently used for the treatment of RRMM. One of the most used regimens includes bendamustine, lenalidomide and dexamethasone that was studied in a Phase $1 / 2$ trial with 23 patients with RRMM (one to three lines of prior therapy). For the study population, the ORR was $47 \%$, median PFS was 10 months and the 2-year OS rate was $65 \% .^{58}$

There are currently no Phase III studies evaluating the efficacy of carfilzomib vs monoclonal antibodies or HDACi, and treatment for each RRMM patient must be individualized. A recent pooled analysis of 20 prospective studies evaluating 2,220 patients reported that the carfilzomib combination regimens produced an ORR of $61 \%$ in 1,211 relapsed/refractory patients and at least a VGPR in 29\%. Alternatively, among the 597 patients receiving panobinostat-containing combinations, the ORR was $49 \%$ and at least $16 \%$ achieved a VGPR. Finally, the ORR of the 449 patients receiving elotuzumabcontaining combinations was $73 \%$ with at least a VGPR in $37 \% .^{59}$ Thus, carfilzomib combination treatment, in the absence of contraindications, should be introduced early on in the treatment of RRMM, as studies have shown deep and prolonged responses even in the absence of ASCT.

\section{Emerging therapies for the treatment of relapsed myeloma}

As discussed earlier, the advent of novel therapies such as IMiDs, PIs and recently, monoclonal antibodies has transformed the treatment paradigm for patients with MM. ${ }^{60}$ Indeed, many of these novel agents (including pomalidomide, carfilzomib, ixazomib, daratumumab, elotuzumab and panobinostat) have already been granted regulatory approval in the relapsed/refractory setting and are routinely used in the clinic.

In addition to the already regulatory-approved PI, two new PIs are being studied in clinical trials: oprozomib and marizomib (Table 3). Oprozomib (PR-047; ONX 0912) is an orally bioavailable tripeptide PI with an epoxyketone subunit, which inhibits the N-terminal threonine active CT-L subunits of the constitutive proteasome and immunoproteasome. ${ }^{61}$ A dose-escalation Phase $1 \mathrm{~b} / 2$ study showed acceptable safety and antitumor activity. The most common grade $3 \mathrm{AE}$ was diarrhea. ${ }^{62}$ More recently, the Phase $1 \mathrm{~b}$ portion of another study with 31 patients, evaluating the safety and efficacy of the combination of oprozomib, pomalidomide and dexamethasone in patients with RRMM showed that this combination has encouraging antimyeloma activity (ORR around 60\% for patients in the study) and is generally well tolerated. ${ }^{63}$ Marizomib (NPI-0052; salinosporamide A) is a PI derived from a marine actinomycete that irreversibly inhibits the three major catalytic activities of the 20S core of the ubiquitin-26S proteasome. This new molecule was tested in a Phase 1 study with 44 patients with hematologic malignancies, including 35 patients with RRMM. The ORR, including minor responses, was about $10 \%$ in efficacy-evaluable RRMM. Marizomib did not exhibit the severe peripheral neuropathy or hematologic toxicity observed with other PIs. ${ }^{64}$ It is currently unclear whether marizomib's drug development program will continue, given that no active studies are currently accruing for the treatment of RRMM.

Fortunately, abundant novel immunotherapies for myeloma are emerging with different mechanisms of action, 
Table 3 Snapshot of forthcoming therapies

\begin{tabular}{|c|c|}
\hline Drug category & Emerging drugs for myeloma \\
\hline \multirow[t]{2}{*}{ PI } & Oprozomib \\
\hline & Marizomib \\
\hline $\mathrm{HDACi}$ & Ricolinostat \\
\hline \multirow[t]{7}{*}{ Monoclonal antibody } & Indatuximab ravtansine \\
\hline & BT062 \\
\hline & GSK28579I6 \\
\hline & Bion I30I \\
\hline & MOR202 \\
\hline & Isatuximab \\
\hline & BBI090I \\
\hline IL-6 inhibitor & Siltuximab \\
\hline HIV protease inhibitor & Nelfinavir \\
\hline Wnt inhibitor & CWP29I \\
\hline $\mathrm{EZH} 2$ inhibitor & GSK28I6I26 \\
\hline Radioisotope & I I3I CLR| 404 \\
\hline KSP inhibitor & Filanesib \\
\hline Hypomethylation of DNA & Azacitidine \\
\hline Hypoxia activated & Evofosfamide \\
\hline SINE & Selinexor, KPT-8602 \\
\hline Virus & Reolysin \\
\hline CTLA-4 inhibitor & Ipilimumab \\
\hline BTK inhibitor & Ibrutinib \\
\hline AKT inhibitor & Afuresertib \\
\hline Checkpoint inhibitors & Pembrolizumab, nivolumab \\
\hline MEK inhibitor & Trametinib \\
\hline $\mathrm{Bcl}-2$ inhibitor & Venetoclax \\
\hline Oncolytic virus & Oncolytic reovirus \\
\hline \multirow[t]{4}{*}{ CAR T-cells } & CTLOI 9 cells \\
\hline & NKG2D \\
\hline & SLAMF7-CAR T-cell \\
\hline & TCRt \\
\hline BiTE & AMG 420 \\
\hline
\end{tabular}

Abbreviations: AKT, protein kinase B; Bcl-2, B-cell lymphoma 2; BiTE, bispecific T-cell engager; BTK, Bruton's tyrosine kinase; CAR, chimeric antigen receptor; CTLA-4, cytotoxic T-lymphocyte-associated protein 4; EZH2, enhancer of zeste homolog 2; HDACi, histone deacetylase inhibitor; HIV, human immunodeficiency virus; IL, interleukin; KSP, kinesin spindle protein; MEK, mitogen-activated protein kinase; PI, proteasome inhibitor; SINE, selective inhibitor of nuclear export; SLAM, signaling lymphocytic activation molecule; SLAMF7, self-ligand receptor of the SLAM family member 7; SYK, spleen tyrosine kinase; TCRt, T-cell receptor-modified T-cells.

such as new monoclonal antibodies, anti-interleukin-6 antibodies, checkpoint inhibitors, cytotoxic T-lymphocyte-associated protein 4 (CTLA-4) inhibitors, vaccines and chimeric antigen receptor (CAR) T-cell therapies. ${ }^{65}$ Figure 1 and Table 3 summarize more exhaustively the different mechanisms of actions of these forthcoming therapies, and the following paragraphs illustrate selected recent and ongoing clinical trials of some of these promising therapies.

Isatuximab, a humanized immunoglobulin G1 anti-CD38 monoclonal antibody, was tested for safety in a Phase I/II study including 96 patients with RRMM. This antibody was overall well tolerated and AEs were mostly related to infusion reactions within 24 hours of isatuximab administration. ${ }^{66}$
A Phase Ib study of isatuximab combined with lenalidomide and dexamethasone in RRMM showed encouraging preliminary efficacy including sCR in $4 \%$ of patients. The ORR was $57 \%$ for patients in the study who were heavily pretreated with a median of four to six lines of therapy, including $85 \%$ IMiD-refractory patients. ${ }^{67}$ A Phase III study of isatuximab with or without lenalidomide is planned.

Pembrolizumab, a programmed cell death-1 inhibitor, combined with lenalidomide and dexamethasone in RRMM was evaluated in a Phase I study for safety and preliminary efficacy. ${ }^{68}$ The ORR for all cohorts was $76 \%$ with a tolerable safety profile, making this a very promising agent for further development in myeloma. A Phase III study of lenalidomide/ dexamethasone with or without pembrolizumab in NDMM with a primary end point of PFS is currently open to accrual and may add to the mounting available therapies for newly diagnosed myeloma (NCT02579863).

Additional promising immunotherapy strategies have been successfully used in acute lymphoblastic leukemia and diffuse large B-cell lymphoma with CAR T-cells. In fact, CAR T-cell therapies for acute lymphoblastic leukemia and diffuse large B-cell lymphoma will be seeking regulatory approval as early as 2017. CARs are engineered molecules that fuse the specificity of a monoclonal antibody with the activation of the T-cell receptor signaling domain. ${ }^{65}$ Data for CAR T-cell therapies in RRMM are promising. A CD19 CAR approach in a patient with RRMM treated with ASCT followed by infusion of autologous T-cells transduced with an anti-CD19 CAR led to a CR with no evidence of progression and no measurable serum or urine monoclonal protein, 12 months after treatment. ${ }^{69}$ Also, a Phase I study using CARs targeting the B-cell maturation antigen (BCMA) in RRMM with a median of seven lines of therapy showed impressive activity at the higher dose levels. Of 12 patients participating in this Phase I dose-escalation study, two patients who were treated at the highest dose levels had significant antimyeloma activity: one patient had an SCR that lasted for 19 weeks before relapse and the other one achieved a VGPR that was ongoing at the last patient's myeloma evaluation at 25 weeks. ${ }^{70}$ Clinical trials to assess the best target and dose for treatment for RRMM are currently ongoing.

Bispecific T-cell engagers (BiTEs) are a new class of medications. They are constructed antibodies that can target tumorassociated surface antigens and T-cell receptor-associated molecular CD3, which leads to activation of immune cells, generating target lysis. BiTEs for MM have only been studied in the preclinical setting. ${ }^{71}$ AMG 420 is a BiTE that targets 


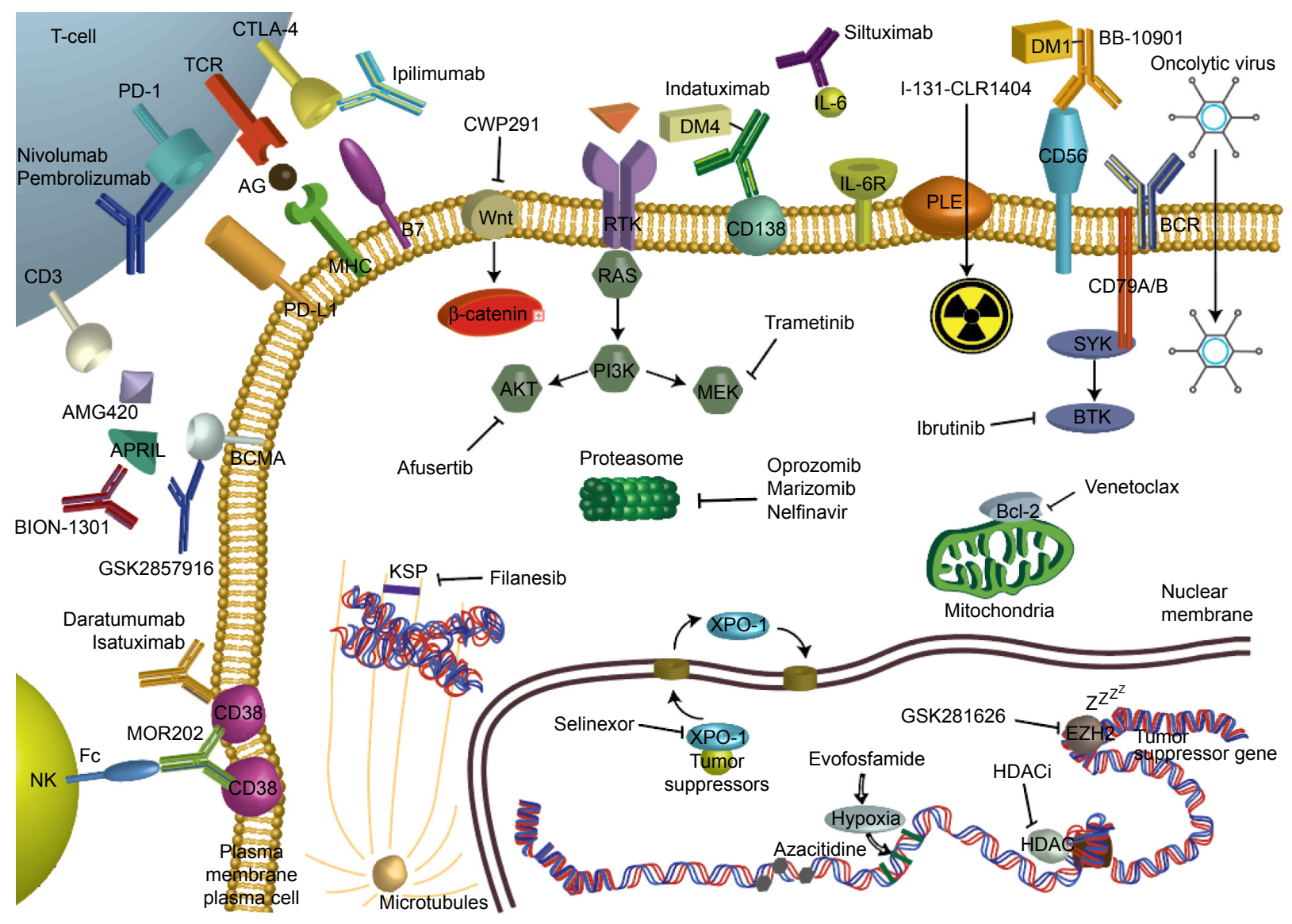

Figure I Depicted mechanisms of action of emerging therapies in the treatment of multiple myeloma.

Abbreviations: AG, antigene; AKT, protein kinase B; APRIL, a proliferation-inducing ligand; Bcl-2, B-cell lymphoma 2; BCMA, B-cell maturation antigen; BCR, B-cell receptor; BiTE, bispecific T-cell engager; BTK, Bruton's tyrosine kinase; CAR, chimeric antigen receptor; CTLA-4, cytotoxic T-lymphocyte-associated protein 4; DM maytansinoid; EZH2, enhancer of zeste homolog 2; Fc, fragment crystallizable; HDAC, histone deacetylase; HDACi, histone deacetylase inhibitor; IL, interleukin; KSP, kinesin spindle protein; MHC, major histocompatibility complex; MEK, mitogen-activated protein kinase; NK, natural killer; PD, programmed cell death; PD-L, programmed deathligand; PI, proteasome inhibitor; PI3K phosphatidylinositide 3-kinases; PLE, phospholipid ethers; SINE, selective inhibitor of nuclear export; SLAM, signaling lymphocytic activation molecule; SLAMF7, self-ligand receptor of the SLAM family member 7; SP, kinesin spindle protein; SYK, spleen tyrosine kinase; TCR, T-cell receptor; TCRt, T-cell receptor-modified T-cells; XPO-I, exportin I.

BCMA. Clinical trials with this agent are expected to be planned and to start accrual within the next $1-2$ years.

\section{Conclusion}

MM is a hematologic malignancy caused by malignant plasma cells. Therapy for MM has significantly changed in the last 2 years with the approval of monoclonal antibodies, HDACi and oral PI. Also, emergent therapies such as CAR T-cells and programmed cell death-1 inhibitors show encouraging early efficacy. Perhaps one of the most important advances made in MM over the past 5 years has been the approval and clinical use of second-generation PIs, such as carfilzomib. Carfilzomib was initially developed to overcome resistance to bortezomib and its side effects, including peripheral neuropathy. The combination of carfilzomib with IMiDs showed in a randomized Phase III study impressive clinical outcomes, even in the absence of ASCT in early myeloma relapse. Based on the efficacy, tolerability and quality of life analysis from this study, the combination of carfilzomib, lenalidomide and dexamethasone might be considered a therapy of choice for patients with one to three prior lines of therapy. Also, results of the Phase III clinical trial comparing bortezomib or carfilzomib with lenalidomide and dexamethasone could render a new standard of care for patients with NDMM.

Patients with relapsed myeloma who had received more than three lines of therapy have a multitude of agents that can be used with good tolerability and efficacy. The choice of agents will depend on availability of clinical trials, eligibility for stem cell transplantation, previous lines of therapy, response to this therapy, aggressiveness of the relapse, side effect profile and patient comorbidities. For example, patients who have high-risk features, including $17 \mathrm{p}$ deletion, could be treated with combinations including pomalidomide, which has shown improved efficacy in this setting. It is important 
to note that enrollment in clinical trials, when possible, should be made a priority so that efficacious agents can move forward to earlier lines of therapy and eventually benefit all patients with MM.

In the future, clinical trials using chemo-immunotherapy in NDMM with a PI, IMiD, steroid and monoclonal antibody may improve the current clinical outcomes. It is yet to be established whether such a combination may render, at least some myeloma patients, cured after initial treatment. Clinical trials clarifying the role and timing of ASCT with these new agents are also needed.

Given the constant development of new molecules and, in particular, with the development of promising immune and cell therapies, treatment for RRMM will continue to evolve at a fast pace. In this scenario, cellular immunotherapies may be a future frontrunner in the therapy of RRMM. More time is needed to compare these novel therapies in a randomized controlled setting to explore their efficacy to standard treatments and to know the exact role for use in the treatment of myeloma.

\section{Disclosure}

The authors report no conflicts of interest in this work.

\section{References}

1. Siegel RL, Miller KD, Jemal A. Cancer statistics, 2016. CA Cancer J Clin. 2016;66(1):7-30.

2. Thumallapally N, Yu H, Asti D, Vennepureddy A, Terjanian T. Salvage therapies in relapsed and/or refractory myeloma: what is current and what is the future? Onco Targets Ther. 2016;9:4843-4858.

3. Kumar SK, Rajkumar SV, Dispenzieri A, et al. Improved survival in multiple myeloma and the impact of novel therapies. Blood. 2008;111(5): 2516-2520.

4. Dimopoulos MA, Richardson PG, Moreau P, Anderson KC. Current treatment landscape for relapsed and/or refractory multiple myeloma. Nat Rev Clin Oncol. 2015;12(1):42-54.

5. Hoy SM. Carfilzomib triple combination therapy: a review in relapsed multiple myeloma. Target Oncol. 2016;11(2):255-262.

6. Manasanch EE, Korde N, Zingone A, et al. The proteasome: mechanisms of biology and markers of activity and response to treatment in multiple myeloma. Leuk Lymphoma. 2014;55(8):1707-1714.

7. Kortuem KM, Stewart AK. Carfilzomib. Blood. 2013;121(6): 893-897.

8. Lee SJ, Levitsky K, Parlati F, et al. Clinical activity of carfilzomib correlates with inhibition of multiple proteasome subunits: application of a novel pharmacodynamic assay. Br J Haematol. 2016;173(6): 884-895.

9. Jakob C, Egerer K, Liebisch P, et al. Circulating proteasome levels are an independent prognostic factor for survival in multiple myeloma. Blood. 2007;109(5):2100-2105.

10. Manasanch EE, de Larrea CF, Zingone A, et al. Enzymatic activities of circulating plasma proteasomes in newly diagnosed multiple myeloma patients treated with carfilzomib, lenalidomide and dexamethasone. Leuk Lymphoma. 2017;58(3):639-645.

11. Korde N, Roschewski M, Zingone A, et al. Treatment with carfilzomiblenalidomide-dexamethasone with lenalidomide extension in Patients with smoldering or newly diagnosed multiple myeloma. JAMA Oncol. 2015;1(6):746-754.
12. History KA. Kyprolis Approval History. Available from: https://www. drugs.com/history/kyprolis.html. Accessed September 16, 2016.

13. FDA. KYPROLIS FDA Prescribing Information. Available from: http:// www.accessdata.fda.gov/drugsatfda_docs/label/2015/202714s009lbl. pdf. Accessed September 13, 2016.

14. EMA. EMA KYPROLIS Information. Available from: http://www.ema. europa.eu/docs/en_GB/document_library?EPAR-Product_Information/ human/003790/WC500197692.pdf. Accessed September 17, 2016.

15. O'Connor OA, Stewart AK, Vallone M, et al. A phase 1 dose escalation study of the safety and pharmacokinetics of the novel proteasome inhibitor carfilzomib (PR-171) in patients with hematologic malignancies. Clin Cancer Res. 2009;15(22):7085-7091.

16. Alsina M, Trudel S, Furman RR, et al. A phase I single-agent study of twice-weekly consecutive-day dosing of the proteasome inhibitor carfilzomib in patients with relapsed or refractory multiple myeloma or lymphoma. Clin Cancer Res. 2012;18(17):4830-4840.

17. Siegel DS, Martin T, Wang M, et al. A phase 2 study of single-agent carfilzomib (PX-171-003-A1) in patients with relapsed and refractory multiple myeloma. Blood. 2012;120(14):2817-2825.

18. Jakubowiak AJ, Siegel DS, Martin T, et al. Treatment outcomes in patients with relapsed and refractory multiple myeloma and high-risk cytogenetics receiving single-agent carfilzomib in the PX-171-003-A1 study. Leukemia. 2013;27(12):2351-2356.

19. Papadopoulos KP, Siegel DS, Vesole DH, et al. Phase I study of 30 -minute infusion of carfilzomib as single agent or in combination with low-dose dexamethasone in patients with relapsed and/or refractory multiple myeloma. J Clin Oncol. 2015;33(7):732-739.

20. Berenson JR, Cartmell A, Bessudo A, et al. CHAMPION-1: a phase $1 / 2$ study of once-weekly carfilzomib and dexamethasone for relapsed or refractory multiple myeloma. Blood. 2016;127(26):3360-3368.

21. Niesvizky R, Martin TG 3rd, Bensinger WI, et al. Phase Ib doseescalation study (PX-171-006) of carfilzomib, lenalidomide, and lowdose dexamethasone in relapsed or progressive multiple myeloma. Clin Cancer Res. 2013;19(8):2248-2256.

22. Wang M, Martin T, Bensinger W, et al. Phase 2 dose-expansion study (PX-171-006) of carfilzomib, lenalidomide, and low-dose dexamethasone in relapsed or progressive multiple myeloma. Blood. 2013; 122(18):3122-3128.

23. Stewart AK, Rajkumar SV, Dimopoulos MA, et al. Carfilzomib, lenalidomide, and dexamethasone for relapsed multiple myeloma. $N$ Engl $J$ Med. 2015;372(2):142-152.

24. Avet-Loiseau H, Fonseca R, Siegel D, et al. Carfilzomib significantly improves the progression free survival of high-risk patients in multiple myeloma. Blood. 2016;128(9):1174-1180.

25. Dimopoulos MA, Moreau P, Palumbo A, et al. Carfilzomib and dexamethasone versus bortezomib and dexamethasone for patients with relapsed or refractory multiple myeloma (ENDEAVOR): a randomised, phase 3, open-label, multicentre study. Lancet Oncol. 2016;17(1):27-38.

26. Shah JJ, Stadtmauer EA, Abonour R, et al. Carfilzomib, pomalidomide, and dexamethasone for relapsed or refractory myeloma. Blood. 2015; 126(20):2284-2290.

27. San Miguel J, Weisel K, Moreau P, et al. Pomalidomide plus low-dose dexamethasone versus high-dose dexamethasone alone for patients with relapsed and refractory multiple myeloma (MM-003): a randomised, open-label, phase 3 trial. Lancet Oncol. 2013;14(11):1055-1066.

28. San-Miguel JF, Hungria VT, Yoon SS, et al. Overall survival of patients with relapsed multiple myeloma treated with panobinostat or placebo plus bortezomib and dexamethasone (the PANORAMA 1 trial): a randomised, placebo-controlled, phase 3 trial. Lancet Haematol. 2016;3(11):e506-e515.

29. San-Miguel JF, Hungria VT, Yoon SS, et al. Panobinostat plus bortezomib and dexamethasone versus placebo plus bortezomib and dexamethasone in patients with relapsed or relapsed and refractory multiple myeloma: a multicentre, randomised, double-blind phase 3 trial. Lancet Oncol. 2014;15(11):1195-1206.

30. Vesole DH, Bilotti E, Richter JR, et al. Phase I study of carfilzomib, lenalidomide, vorinostat, and dexamethasone in patients with relapsed and/or refractory multiple myeloma. Br J Haematol. 2015;171(1):52-59. 
31. FARYDAK FDA Prescribing information. Available from: http:// www.accessdata.fda.gov/drugsatfda_docs/label/2015/205353s000lbl. pdf?et_cid=35529885\&et_rid=931330620\&linkid=http $\% 3 \mathrm{a} \% 2 \mathrm{f} \% 2 \mathrm{f}$ www.accessdata.fda.gov\%2fdrugsatfda_docs $\% 2$ flabel $\% 2$ f2015\%2f2 05353s000lbl.pdf. Accessed August 25, 2016.

32. Berdeja JG, Gregory TB, Faber E, et al. 4530 a phase I/II study of the combination of panobinostat and carfilzomib in patients with relapsed or relapsed/refractory multiple myeloma (MM).: final analysis of second dose expansion. Presented at: 58th Annual Meeting and Exposition; December 3-6 2016; San Diego, CA. Accessed December 21, 2016.

33. Brown S, Hinsley S, Ballesteros M, et al. The MUK five protocol: a phase II randomised, controlled, parallel group, multi-centre trial of carfilzomib, cyclophosphamide and dexamethasone (CCD) vs. cyclophosphamide, bortezomib (Velcade) and dexamethasone (CVD) for first relapse and primary refractory multiple myeloma. BMC hematol. 2016;16:14.

34. Gramatzki M, Günther A, Offidanani M, et al. Carfilzomib in combination with bendamustine and dexamethasone (CBd) in relapsed and/ or refractory patients with multiple myeloma: the phase I/II EMN09 study. Blood. 2016;128:3334. Accessed December 12, 2016.

35. Fiala MA, Keller J, Sekhar J, et al. 3329 A Phase II Study of carfilzomib, pegylated liposomal doxorubicin, and dexamethasone for relapsed or refractory multiple myeloma. Presented at: 58th Annual Meeting and Exposition; December 3-6, 2016; San Diego, CA. Accessed December 21, 2016.

36. Zhang K, Desai A, Zeng D, Gong T, Lu P, Wang M. Magic year for multiple myeloma therapeutics: key takeaways from the ASH 2015 Annual Meeting. Oncotarget. 2016. Epub 2016 Nov 11.

37. Ameican Society of Hematology. 973 Final results of phase 1 MMRC trial of selinexor, carfilzomib, and dexamethasone in relapsed/ refractory multiple myeloma (RRMM). Available from: https:// ash.confex.com/ash/2016/webprogram/Paper93704.html. Accessed December 20, 2016.

38. Jakubowiak A, Jasielec J, Rosenbaum CA, et al. Phase 1 MMRC trial of selinexor, carfilzomib (CFZ), and dexamethasone (DEX) in relapsed and relapsed/refractory multiple myeloma (RRMM). Blood. 2015;126(23):4223.

39. Jakubowiak AJ, Dytfeld D, Griffith KA, et al. A phase $1 / 2$ study of carfilzomib in combination with lenalidomide and low-dose dexamethasone as a frontline treatment for multiple myeloma. Blood. 2012;120(9): 1801-1819.

40. Myeloma NGVM. Available from: https://www.nccn.org/professionals/ physician_gls/pdf/myeloma.pdf. Accessed August 21, 2016.

41. Bringhen S, Petrucci MT, Larocca A, et al. Carfilzomib, cyclophosphamide, and dexamethasone in patients with newly diagnosed multiple myeloma: a multicenter, phase 2 study. Blood. 2014;124(1): 63-69.

42. Stewart AK, Dimopoulos MA, Masszi T, et al. Health-related quality of life results from the open-label, randomized, phase III ASPIRE trial evaluating carfilzomib, lenalidomide, and dexamethasone versus lenalidomide and dexamethasone in patients with relapsed multiple myeloma. J Clin Oncol. 2016. Epub 2016 Sep 6.

43. Hasinoff BB, Patel D, Wu X. Molecular Mechanisms of the Cardiotoxicity of the Proteasomal-Targeted Drugs Bortezomib and Carfilzomib. Cardiovasc Toxicol. 2016. Epub 2016 Jul 7.

44. Chari A, Hajje D. Case series discussion of cardiac and vascular events following carfilzomib treatment: possible mechanism, screening, and monitoring. BMC Cancer. 2014;14:915.

45. FDA. Available from: http://www.accessdata.fda.gov/drugsatfda_docs/ label $/ 2012 / 2027141$ bl.pdf?et_cid $=29661884 \&$ et_rid $=463638624 \&$ linkid=http $\% 3 \mathrm{a} \% 2 \mathrm{f} \% 2 \mathrm{fwww}$.accessdata.fda.gov\%2fdrugsatfda docs $\% 2$ flabel $\% 2$ f2012\%2f202714lbl.pdf\%20(Accessed $\% 20$ on $\% 20$ August $\% 2013, \% 202012$ ). Accessed August 15, 2016.

46. Atrash S, Tullos A, Panozzo S, et al. Cardiac complications in relapsed and refractory multiple myeloma patients treated with carfilzomib. Blood Cancer J. 2015;5:e272.

47. Mikhael J. Management of carfilzomib-associated cardiac adverse events. Clin Lymphoma Myeloma Leuk. 2016;16(5):241-245.
48. Hajek R, Masszi T, Petrucci MT, et al. A randomized phase III study of carfilzomib vs low-dose corticosteroids with optional cyclophosphamide in relapsed and refractory multiple myeloma (FOCUS). Leukemia. 2016; 31(1):107-114.

49. Lonial S, Weiss BM, Usmani SZ, et al. Daratumumab monotherapy in patients with treatment-refractory multiple myeloma (SIRIUS): an openlabel, randomised, phase 2 trial. Lancet. 2016;387(10027):1551-1560.

50. Plesner T, Arkenau HT, Gimsing P, et al. Phase 1/2 study of daratumumab, lenalidomide, and dexamethasone for relapsed multiple myeloma. Blood. 2016. Epub 2016 Aug 16.

51. Palumbo A, Chanan-Khan A, Weisel K, et al. Daratumumab, Bortezomib, and Dexamethasone for multiple myeloma. NEngl JMed. 2016; 375(8):754-766.

52. FDA. Available from: http://www.accessdata.fda.gov/drugsatfda_docs/ label/2015/761035s000lbl.pdf?et_cid=37060330\&et_rid=931330620\& linkid=http $\% 3 \mathrm{a} \% 2 \mathrm{f} \% 2 \mathrm{fwww}$.accessdata.fda.gov $\% 2$ fdrugsatfda_docs $\%$ 2flabel\%2f2015\%2f761035s000lbl.pdf. Accessed August 18, 2016.

53. Lonial S, Dimopoulos M, Palumbo A, et al. Elotuzumab therapy for relapsed or refractory multiple myeloma. $N$ Engl J Med. 2015;373(7): 621-631.

54. Baz RC, Martin TG 3rd, Lin HY, et al. Randomized multicenter phase 2 study of pomalidomide, cyclophosphamide, and dexamethasone in relapsed refractory myeloma. Blood. 2016;127(21):2561-2568.

55. Moreau P, Masszi T, Grzasko N, et al. Oral ixazomib, lenalidomide, and dexamethasone for multiple myeloma. $N$ Engl J Med. 2016;374(17): 1621-1634.

56. Krishnan A, Kapoor P, Palmer J, et al. 3316 A phase I/II trial of ixazomib (Ix), pomalidomide (POM), and dexamethasone (DEX), in relapsed/ refractory $(\mathrm{R} / \mathrm{R})$ multiple myeloma $(\mathrm{MM})$ patients: responses in double/ triple refractory myeloma and poor risk cytogenetics. Accessed December 12, 2016.

57. Kumar S, Grzasko N, Delimpasi S, et al. 3327 Phase 2 study of the all-oral combination of ixazomib plus cyclophosphamide and low-dose dexamethasone (ICd) in patients (Pts) with relapsed/refractory multiple myeloma (RRMM). Accessed December 12, 2016.

58. Pozzi S, Gentile M, Sacchi S, et al. Bendamustine, Low-dose dexamethasone, and lenalidomide (BdL) for the treatment of patients with relapsed/refractory multiple myeloma confirms very promising results in a phase I/II study. Leuk Lymphoma. 2016:1-8.

59. Liu L, Zhao N, Xu W, Sheng Z, Wang L. Pooled analysis of the reports of carfilzomib, panobinostat, and elotuzumab combinations in patients with refractory/relapsed multiple myeloma. J Hematol Oncol. 2016;9(1):54.

60. Gonsalves WI, Milani P, Derudas D, Buadi FK. The next generation of novel therapies for the management of relapsed multiple myeloma. Future Oncol. 2017;13(1):63-75.

61. Infante JR, Mendelson DS, Burris HA 3rd, et al. A first-in-human doseescalation study of the oral proteasome inhibitor oprozomib in patients with advanced solid tumors. Invest New Drugs. 2016;34(2):216-224.

62. Ghobrial MD, Irene M, Kaufman JL, et al. Clinical Profile of SingleAgent Modified-Release Oprozomib Tablets in Patients (Pts) With Hematologic Malignancies: Updated Results From a Multicenter, Open-Label, Dose Escalation Phase 1b/2 Study. ASH 2013 Annual Meeting Abstract 3184; December 8; 2013; Washington, DC.

63. Shah J, Niesvizky R, Stadtmauer E, et al. Pomalidomide, and Dexamethasone (OPomd) in patients (Pts) with relapsed and/or refractory multiple myeloma (RRMM): initial results of a phase $1 \mathrm{~b}$ study. Blood. 2015;126(23):378.

64. Richardson PG, Zimmerman TM, Hofmeister CC, et al. Phase 1 study of marizomib in relapsed or relapsed and refractory multiple myeloma: NPI-0052-101 part 1. Blood. 2016;127(22):2693-2700.

65. Hoyos V, Borrello I. The immunotherapy era of myeloma: monoclonal antibodies, vaccines and adoptive T cell therapies. Blood. 2016;128(13): 1679-1687.

66. Martin T, Richter J, Vij R, et al. A dose finding phase II trial of isatuximab (SAR650984, Anti-CD38 mAb) as a single agent in relapsed/ refractory multiple myeloma. Blood. 2015;126:509. 
67. Vij R, Lendvai N, Martin T, et al. A phase Ib trial of isatuximab plus lenalidomide and dexamethasone in relapsed/refractory multiple myeloma: interim results from 2 new dose cohorts. JCO. 2016; 34:2016.

68. San Miguel J, Mateos MV, Shah J, et al. Pembrolizumab in combination with lenalidomide and low-dose dexamethasone for relapsed/refractory multiple myeloma (RRMM): Keynote-023. Blood. 2015;126:505.

69. Garfall AL, Maus MV, Hwang WT, et al. Chimeric antigen receptor T cells against CD19 for multiple myeloma. NEngl JMed. 2015;373(11): 1040-1047.

70. Ali SA, Shi V, Maric I, et al. T cells expressing an anti-Bcell-maturation-antigen chimeric antigen receptor cause remissions of multiple myeloma. Blood. 2016;128(13):1688-1700.
71. Zou J, Chen D, Zong Y, et al. Immunotherapy based on bispecific T-cell engager with hIgG1 Fc sequence as a new therapeutic strategy in multiple myeloma. Cancer Sci. 2015;106(5):512-521.

72. Martin TG, Mannis GN, Chari A, Munster P, Campana F, Hui A-M, et al. Phase Ib Study of Isatuximab and Carfilzomib in Relapse and Refractory Multiple Myeloma. Blood. 2016;128(22):2111.

73. Plesner T, Arkenau H-T, Gimsing P. Daratumumab in Combination with Lenalidomide and Dexamethasone in Patients with Relapsed or Relapsed and Refractory Multiple Myeloma: Updated Results of a Phase 1/2 Study (GEN503). Blood. 2015;126:507. Abstract 0507.

\section{Publish your work in this journal}

OncoTargets and Therapy is an international, peer-reviewed, open access journal focusing on the pathological basis of all cancers, potential targets for therapy and treatment protocols employed to improve the management of cancer patients. The journal also focuses on the impact of management programs and new therapeutic agents and protocols on

\section{Dovepress}

patient perspectives such as quality of life, adherence and satisfaction. The manuscript management system is completely online and includes a very quick and fair peer-review system, which is all easy to use. Visit http://www.dovepress.com/testimonials.php to read real quotes from published authors.

Submit your manuscript here: http://www.dovepress.com/oncotargets-and-therapy-journal 